3. A New Species of Biattoid (Archimylacris) from the Keele Group (Radstockila ) of Shropshire. By Herbert Boltox, M.Sc., F.R.S.E., F.G.S. (Read February 2nd, 1921.)

\title{
[Plate I.]
}

I AM indebted to the Geological Survey for the opportunity of examining a fragment of an insect-wing discovered by Mr. J. Pringle, F.G.S., while engaged in the examination of corematerial collected in 1919 by Mr. T. C. Cantrill, B.Sc., F.G.S., from a new borehole for water at Slang Lane, Wellington (Shropshire). ${ }^{1}$

The core-material came from some level between the surface and 97 feet, the actual depth being undeterminable because the chisel was used in boring. From an examination of the plantremains, Mr. Pringle is of opinion, and Mr. Cantrill's fieldobservations bear him out, that the beds belong to the Keele Group.

The wing-fragment and its impression lie upon the surfaces of two pieces of red marl, and are not easily recognizable. Its discovery by Mr. Pringle is testimony to the thoroughness of his search of the material.

Enough of the wing is present to enable us to determine the genus, and to show that the form is new to British Coal Measures, and sufficiently distinct from Continental species to merit specific distinction. The characters of the subcosta and the interstitial neuration clearly indicate that the wing belongs to the genus Archimylacris, and as such I describe it.

\section{ARChIMTLACRIS PRINGLeI, sp. nov.}

Holotype.-The basal two-thirds, and impression of a tegmen or forewing, lying upon the irregular surface of two small pieces of red marl, and partly obscured by plant-remains. Length $=18 \mathrm{~mm}$. Collection of the Geological Survey, Jermyn Street, Reg. Nos. 30725-726.

Horizon and locality.-Keele Group, Upper Division of the Coal Measures; from rocks between the surface-level and $\mathbf{9 7}$ feet in the borehole at Slang Lane, Wellington (Shropshire).

Specific description.-Wing twice, or two and a half times, as long as wide. Outer margin flatly curved; subcosta strapshaped, and giving off numerous parallel branches to the outer margin. Radius dividing just beyond the middle of the wing, and giving off a radial sector. Median parallel to the radius, and

1 'Summary of Progress for 1919' Mem. Geol. Surv, 1920, p. 8. 
[vol. lxxvii,

dividing a little farther out than the radius; evidently reaching the inner half of the wing-margin. Cubitus curving gently inwards, and giving off inward branches, only four of which are shown. Anal area long, and reaching to the end of the basal third of the inner margin. Integument thin, interstitial neuration of close parallel cross-nervures, except in the basal area, where the neuration becomes reticulate.

Description.-C'The eostal margin is well defined, flatly convex over the greater part of its length, and well rounded into the point of attachment. The subeosta is parallel to, and widely spaced from, the costal margin, and extends over two-thirls of the length of the wing. It gives off eight or nine oblique and parallel

Fig. 1.-Archimylacris pringlei, sp. nov. $\times 3$.

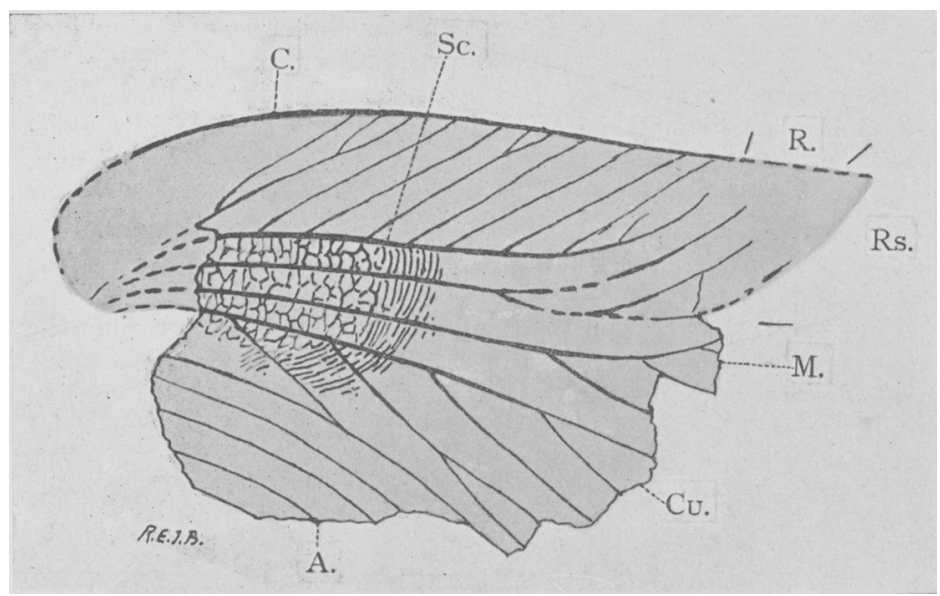
A. = Anal.
C. $=$ Costa.
Sc. $=$ Subcosta.
R. = Radius
Rs. $=$ Radial sector.
M. = Median .

branches, all reaching the margin. The first branch is represented only by a small fragment of the middle of its length; the second forks twice into three twigs, while the third, fourth, and fifth fork near the margin. There is also a small undeveloped ramus, branching off from the subcosta at the point where the latter bends forwards towards the margin.

The radius is incomplete, the main stem diverging slightly from the subcosta, and dividing by a wide fork at a point between the seventh and eighth branches of the subcosta. The first of the radial divisions is the true radius, and the inner branch is the radial sector. The radius can be traced almost up to the margin, and shows a single forking. The radial sector goes out in a straight line to the wing-apex. The median has a slight divergence from 
the radius, and is closer to it than is the latter to the subcosta. It gives off the first inward branch a little distance from the point of origin of the radial sector, and feeble traces of a second branch can be discerned farther out. It must have possessed from four to six branches, adequately to support the area of the wing to which it is directed.

The cubitus starts out from the middle of the base of the wing, gradually bending inwards in its course to the most distal part of the inner margin. Four in wardly directed branches are given off, the first passing under the first anal, owing to the fracture of the wing. The second divides by a simple fork in the middle of its length, while the third and fourth are undivided. All the branches of the cubitus come off at wide angles, and so the area enclosed by this vein is large.

Fig. 2.-Archimylacris desaillyi Leriche. $\times 3$.

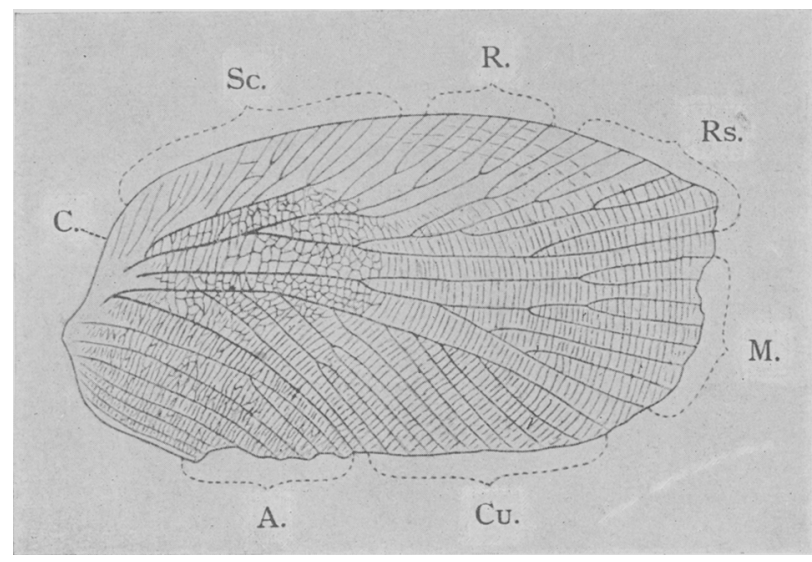
A. = Anal.
C. $=$ Costa.
Sc. $=$ Subcosta.
R. = Radius. 3
Rs. = Radial sector
M. = Median.

The anal area has broken away from the rest of the wing, and moved a little forwards, overlapping the first branch of the cubitus. The anal furrow is no longer distinguishable, having lain along the line of fracture. Six anal veins are present, the first somewhat obscure, and the second and third possibly united at their base.

The interstitial neuration consists of a compact series of closeset transverse nervures, which, in the basal areas between the radius, median, and cubitus, anastomose laterally, forming a fine network.

Affinities.-I was at once struck with the likeness of this specimen to the form described by Leriche, ${ }^{1}$ as Archimylacris

1 Ann. Soc. Géol. Nord, vol. xxxvi (1907) p. 164 \& pl. ii. 
desaillyi, and therefore sent an enlarged photograph of the specimen to Dr. P. Pruvost, Lille University, in whose custody Leriche's type now is. Dr. Pruvost recognized the likeness, but thought that it was more closely allied to a form referred by himself first to $A$. belgica Handlirsch, and later described by him as a new species, $A$. lerichei. ${ }^{1}$

Dr. Pruvost takes note of one feature which has caused me to regard the specimen as nearer to $A$. desaillyi than to $A$. lerichei, namely, the great differences in the form of the distal end of the costal vein. In $A$. lerichei, the subcostal is not sharply bent outwards as in this specimen and in $A$. desaillyi, but is decidedly oblique, so that the costal area is much less strap-shaped than in either. Nor is the general course of the subcosta so truly parallel to the margin.

\section{Tabulated Comparison.}

\section{A. pringlei, sp. nov.}

Costal Area.

Strap-shaped, widely spaced from wing-margin.

Subeostal Vein.

Numerous divisions, mostly forking.

\section{Radius Vein.}

Few branches. Radial sector arising opposite outer fourth of subcosta.

\section{Radial Sector. \\ Branching not known.}

Median Vein.

Branches beyond origin of radial sector.

Cubitus Vein.

First branch simple, second forked.

\section{Anal Veins. \\ Undivided.}

\section{Interstitial neu.} ration.

Transverse nervures, except in the median basal part of the wing, where it is reticulate.

\section{$A$. desaillyi Leriche.}

Strap-shaped, widely spaced from wing-margin.

Numerous divisions, mostly forking.

Seven branches.

Radial sector arising opposite onter third of subcosta.

Eight branches.

Branches opposite first fork of radial sector.

First branch simple, second and third forked.

First vein only forked.

Transverse nervures, except in the median basal part of the wing, where it is reticulate.

\section{A. lerichei Pruvost.}

Outer third oblique to wing-margin.

Few divisions, much branched.

Twelve branches. Radial sector arising opposite middle of subcosta.

Seven to eight branches.

Branches much beyond origin of radial sector.

First branch dividing into four, second simple, third and fourth branched.

First anal forking
twice.

Transverse nervures, except in the median basal part of the wing, where it is reticulate.

1 'Les Insectes Houillers du Nord de la France' Ann. Soc. Géol. Nord, vol. xli (1912) p. 335 \& pl. ix, figs. 4-4a; see also 'Introduction à l'Étude du Terrain Houiller du Nord du Pas-de-Calais : La Faune Continentale du Terrain Houiller du Nord de la France' Paris, 1919 [1920], p. 154 \& pl. viii, figs. 5-6, 
It is evident that the relationship between these three species is very close, yet the British specimen is clearly distinct. I have much pleasure in giving Mr. Pringle's name to the species discovered by him.

Observations.--The occurrence of a fossil Blattoid in Measures formerly regarded as Permian, and now classed as Upper Coal Measures, is worthy of comment, especially as the fossil is more closely related to Blattoids found in the Ccal Measures of Liévin, Northern France, than to any British species. The Coal Measures of Liévin are generally accepted as being at the summit of the Westphalian Series. Dr. Pruvost writes that he has previously

Fig. 3.-Archimylacris lerichei Pruvost. $\times 3$.

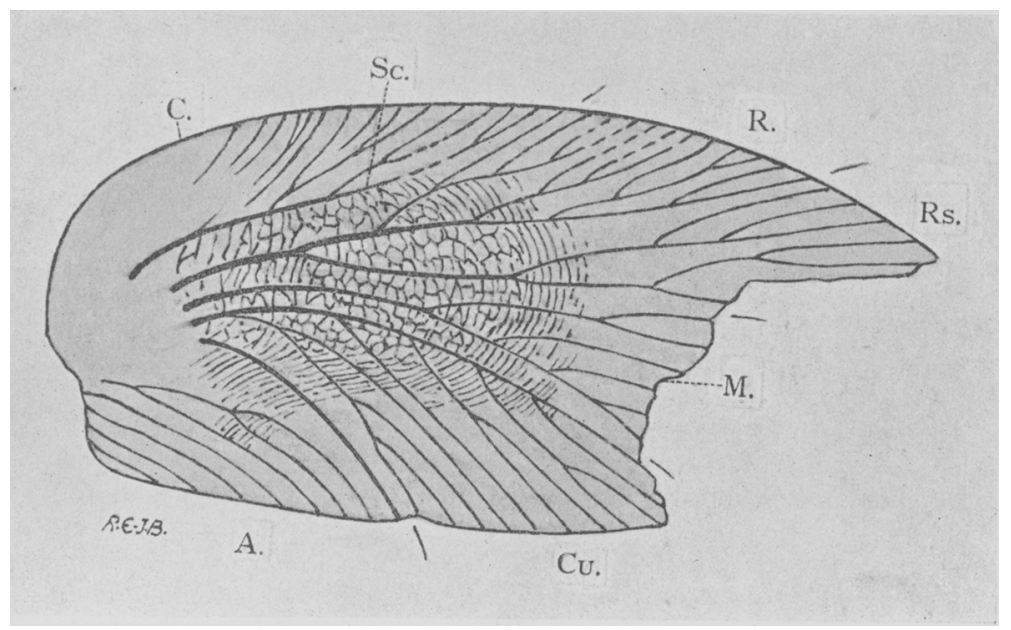

[For explanation of lettering, see fig. 2, p. 25.]

drawn attention to the fact that the fauna at the top of the Coal Measures in Great Britain (Keele Group, Newcastle-under-Lyme Group, Etruria Group) does not differ (except in the presence of Anthracomya calcifera, peculiar to England) from the fauna at the top of the Westphalian in Northern France. The occurrence of an Archimylacris in the Keele Group confirms him in this opinion.

The Keele Group in which the insect-wing was found was formerly regarded as Permian, and is so marked upon the older geological maps; but the researches of the Survey Officers, as also the palæobotanical work of the late Dr. Newell Arber, and more especially that of Dr. Kidston, have conclusively proved their CoalMeasure character. These workers regard the Keele Group as part of a true Upper Coal-Measure Series, widely spread over 
Shropshire and adjacent counties. Dr. Kidston ${ }^{1}$ has given the name 'Radstockian' to the Series which includes the Keele Group.

I desire to express my indebtedness to Mr. T. C. Cantrill, who collected the core-material, afterwards supplied me with information concerning the Keele Group, and checked my statements as to the stratigraphy.

\section{EXPLANATION OF PLATE I.}

Archimylacris minglei, sp. nov. Wing-fragment and impression magnified $4 \cdot 8$ diameters.

\section{Discussios.}

Dr. J. W. Eravs asked what was the earliest horizon at which insect-remains were found, and whether they showed from the first a variety of different types.

Mr. E. E. I. Drrox congratulated the Author on his successful determination of the affinities of the Blattoid. and Mr. Pringle on having added another to his long list of 'captures' of CoalMeasure arthropods. He contrasted the conformity that existed between the Keele Group and the underlying part of the Coal Measures with the unconformable relations of the Continental Stephanian, and mentioned the difference between the correlation of Dr. R. Kidston, who referred the Keele Group to the Stephanian, and that of the late Dr. E. A. Newell Arber, who regarded the group as the top of the Westphalian. Every piece of zonal evidence was, therefore, important, and he enquired whether the degree of specialization of the Wellington Blattoid had enabled the Author to compare its age with those of Liévin, the age of which was known.

The Avrror thanked the Fellows for their kind reception of his paper, and, in answer to Dr. J. W. Evans, replied that some doubt existed as to the earliest possible occurrence of fossil insects. Brongniart had recorded the wing of a supposed Blattoid from the Silurian, under the name of Palaoblattina douvillei, though the general opinion was that the structure was not of insect origin, but in all probability a portion of a cephalic spine of a trilobite. Sir J. W. Dawson recorded the existence of undoubted insect-remains in the Fern Ledges of New Brunswick, and classed the deposits as Devonian. The recent researches of Dr. Marie Stopes had, however, shown that they were of Carboniferous age.

Undoubted insect-remains have not as yet been recorded from any rocks older than the Upper Carboniferous, where they appear in considerable numbers. They show a degree of specialization such as could hardly have been reached without a long ancestry. This was especially true of the Blattoids, and for this reason the Author believed that insect life must have first appeared at a much

1 Q. J. G. S. vol. lxi (1905) p. 319. 
Downloaded from http://jgslegacy.lyellcollection.org/ at University College London on July 4, 2016

Quart. Journ. Geol. Soc. Vol. LXXVII, Pl. I.

Fig. I. $\times 4.8$

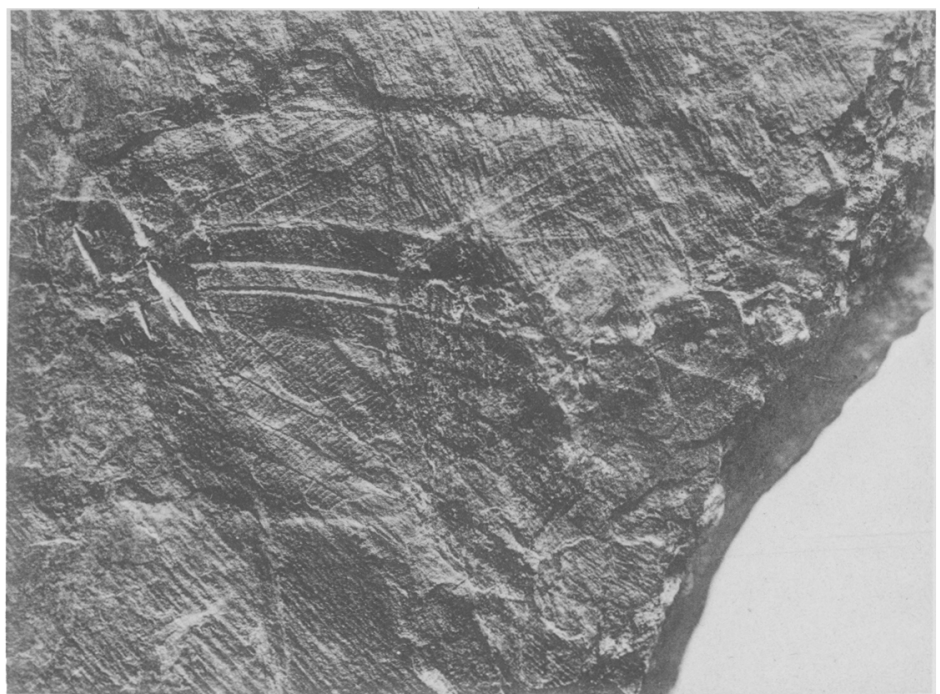

Fig. 2. $\times 4 \cdot 8$

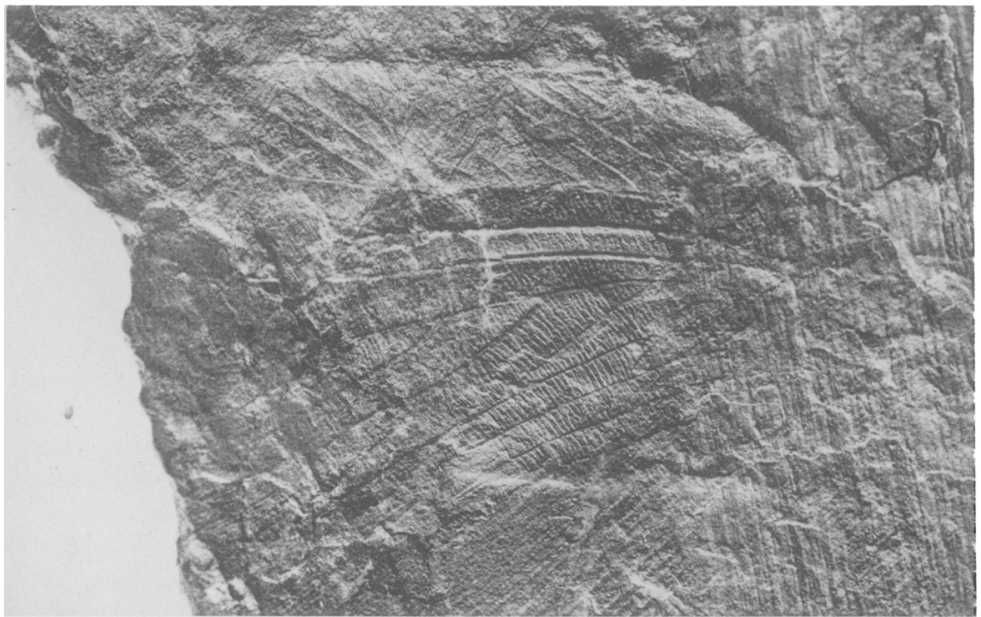

J.W. Tutcher, Photo.

Bemrose, Collo., Derby. 
earlier period. He was firmly convinced that the most primitive insects would yet be found in Devonian rocks, or in the Upper Silurian. The oldest insect forms known are generalized types that have no direct relation with living orders of insects. Their interrelationships are not at all well understood, and the greater number of them are grouped into a class, Palæodictyoptera, which serves rather as a dumping-ground than as the expression of an understood classification. Blattoid forms are numerous, and of great variety, their specialization having proceeded far beyond a primitive condition.

In answer to Mr. Dixon, the Author said that the Wellington Blattoid had the same degree of specialization as the two species compared with it from Liévin. It was, indeed, very closely related to them, much more so than to any British species yet known. A similar degree of specialization and relationship had been established between Soomylacris deanensis of the Forest of Dean Coalfield, S. burri of the Kent Coalfield, and S. lievinensis from the insectbeds of Liévin. Similarly, Meganeura (Boltonites, Handlirsch) radstockensis was closely related to $M$ I. mony $i$ of the Coal Measures of Commentry. 